\title{
Matriz bidimensional de celulose obtida de folha vegetal visando reparo ósseo: caracterização morfológica e química
}

\author{
Bidimensional matrix of cellulose obtained \\ from vegetable leaf aiming bone repair: \\ morphological and chemical characterization
}

Paula Pereira de Souza Vaz ${ }^{1}$, Rudolf Huebner ${ }^{2}$, Hermes de Souza Costa ${ }^{1}$

\begin{abstract}
${ }^{1}$ Departamento de Engenharia de Materiais - Centro Federal de Educação Tecnológica de Minas Gerais, DEMAT/CEFET-MG, Av. Amazonas, 5253, Nova Suíça, CEP: 30421-169, Belo Horizonte, MG, Brasil. ${ }^{2}$ Departamento de Engenharia Mecânica - Universidade Federal de Minas Gerais, DEMEC/UFMG, Av. Antônio Carlos, 6627, Bloco 1, $3^{\circ}$ andar, Campus Pampulha, Belo Horizonte, MG, Brasil.

e-mail: ppsouza87@gmail.com, hermessc@bol.com.br, rudolf@demec.ufmg.br
\end{abstract}

\begin{abstract}
RESUMO
A cirurgia ortopédica maxilofacial tem como um de seus maiores desafios a reparação óssea efetiva, principalmente em casos de perdas teciduais extensas por diversas causas. Atualmente, a grande demanda por transplantes e enxertos de órgãos e tecidos tem impulsionado a busca por materiais capazes de atuar no processo de reparação tecidual. Os biomateriais têm como finalidade, através do contato com a interface dos sistemas biológicos, avaliar, tratar, aumentar ou substituir um tecido, órgão ou função do corpo. Dessa forma, tomando por base a arquitetura, biocompatibilidade da matriz extracelular de celulose, bem como a presença de sistema vascular na estrutura de folhas de espinafre, é proposta a investigação de um tratamento químico visando sua utilização como suporte para crescimento de tecido humano periosteal. Neste contexto, a celulose aparece como uma opção cada vez mais pesquisada em função de suas características de biodegradabilidade, biocompatibilidade, baixo custo e por ser uma alternativa sustentável. Diferentes formas de celulose isolada e seus derivados, assim como associadas a outros biomateriais, têm sido cada vez mais pesquisadas para uso como matriz em processos de reparação tecidual. Considerando as características da celulose como biomaterial, esse estudo visa caracterizar a folha vegetal nativa e após processo químico utilizando soluções iônicas e não-iônicas, estabelecendo análise comparativa das alterações provocadas pelo processamento e seu potencial para utilização como matriz bidimensional em reparo de tecido ósseo. Foram utilizadas técnicas de imersão e perfusão em detergentes como protocolos, além de exposição de algumas amostras em glutaraldeído, tendo como finalidade a reticulação da matriz polimérica, bem como imersão em fluido corporal simulado (SBF-Simulated Body Fluid). Os materiais resultantes dos processamentos químicos foram submetidos às análises de microscopia eletrônica de varredura (MEV), espectroscopia de absorção na região de infravermelho (FTIR), análise termogravimétrica (TGA) e análise térmica diferencial (DTA). Ao final das caracterizações concluiu-se que o protocolo utilizado é uma opção viável para o processamento da celulose, de baixo custo, que produz alterações estruturais aceitáveis no produto final, porém ensaios como a quantificação de ácido desoxirribonucleico vegetal e ensaios de citotoxicidade são sugeridos como complementação.
\end{abstract}

Palavras-chave: Celulose, biomateriais, matriz.

\footnotetext{
ABSTRACT

Maxillofacial orthopedic surgery have as one of its biggest challenges the effective bone repair, especially in cases of extensive loss of bone tissue due to several causes. Currently, the high demand for organ and tissue transplants and grafts has driven the search for materials capable of acting in the tissue repair process. Through contact with the interface of biological systems, biomaterials aim to evaluate, treat, augment or replace a body tissue, organ or function. Therefore, based on the architecture, biocompatibility of the
} 
cellulose extracellular matrix, as well as the presence of vascular system in the structure of spinach leaves, it is proposed to investigate a chemical treatment aiming at its use as a support for periosteal human tissue growth. In this context, cellulose appears as an option due to its characteristics of biodegradability, biocompatibility, low cost and for being a sustainable alternative. Different forms of isolated cellulose and its derivatives, as well as associated with other biomaterials, have been increasingly researched for use as a matrix in tissue repair processes. Considering the characteristics of cellulose as biomaterial, this study aims to characterize a plant leaf in the native form and after chemical process using ionic and nonionic solutions, establishing comparative analysis of the changes caused by processing and its potential for use as a twodimensional matrix in bone tissue repair. Detergent immersion and perfusion techniques were used as protocols, as well as exposure of some samples to glutaraldehyde, with the purpose of cross-linking the polymeric matrix, as well as immersion in simulated body fluid (SBF). The materials resulting from chemical processing were subjected to scanning electron microscopy (SEM), Fourier transform infrared spectroscopy (FTIR), thermogravimetric analysis (TGA) and differential thermal analysis (DTA). At the end of the characterizations, it was concluded that the protocol used is a viable option for low cost cellulose processing, which produces acceptable structural changes in the final product, but assays as deoxyribonucleic acid (DNA) quantification and cytotoxicity tests are suggested.

Keywords: Cellulose, biomaterials, matrix.

\section{INTRODUÇÃO}

A reparação óssea é um importante problema enfrentado pela cirurgia ortopédica maxilofacial em função de danos causados por tumores, infecções extensas, malformações ou perda óssea por traumas [1]. Enquanto alguns traumas do tecido ósseo possuem capacidade de auto reparação, alguns defeitos considerados críticos, com espessura média de $2 \mathrm{~cm}$ ou mais de diâmetro, não apresentam essa habilidade espontânea [2]. Um dos principais responsáveis pelo processo de reparação de fraturas é o periósteo, tecido especializado altamente vascularizado, que envolve a superfície dos ossos, sendo composto por tecido conjuntivo rico em fibras e vasos e por uma camada interna onde residem células progenitoras derivadas do periósteo (PDPC) [3].

Nos últimos anos intensificaram-se as pesquisas que buscam conhecer e aperfeiçoar características físicas, químicas, morfológicas e biológicas dos biomateriais, materiais que têm como finalidade, através do contato com a interface dos sistemas biológicos, avaliar, tratar, aumentar ou substituir um tecido, órgão ou função do corpo. O objetivo é utilizar esses materiais como estrutura nos processos de reparação tecidual, distribuição controlada de medicamentos, entre outras [4].

Dentre os biomateriais utilizados na confecção de matrizes artificiais está a celulose, polímero natural renovável, biodegradável e biocompatível que possui como principais fontes estruturas de plantas, bactérias, fungos e animais marinhos. Largamente utilizada na indústria de produção de papel, em função de suas propriedades físico-químicas, têm despertado interesse na produção de novos materiais em várias áreas, como energia, eletrônica, comunicação e medicina $[5,6]$.

A celulose de forma isolada ou seus derivados, como nano e microcristais, acetato de celulose, carboximetil celulose, hidroxietil celulose, propionato de celulose, assim como sua associação a outros biomateriais como hidroxiapatita, têm sido consideradas alternativas sustentáveis aos polímeros sintéticos em vários tipos de indústria e também na área biomédica [6].

Dessa forma, este trabalho visa caracterizar química e morfologicamente a matriz bidimensional de celulose obtida através de processamento químico de folha de espinafre utilizando soluções iônicas e nãoiônicas pelas técnicas de imersão e perfusão, visando desenvolvimento de estrutura capaz de atuar no processo de reparação óssea, mimetizando as funções do periósteo. Além dos detergentes, algumas amostras foram submetidas também a ensaios com fluido corporal simulado (SBF-Simulated Body Fluid) e à ensaio de reticulação, tendo o glutaraldeído como agente. As técnicas de caracterização utilizadas foram a microscopia eletrônica de varredura (MEV), que permite avaliação microestrutural do material antes e após o tratamento, da afinidade da estrutura para precipitação de fosfato de cálcio quando exposta à SBF, e da efetividade de reticulação da estrutura quando em contato com glutaraldeído; análise termogravimétrica (TGA) e análise térmica diferencial (DTA) permitindo análise do comportamento térmico de folhas nativas e tratadas; espectroscopia de absorção na região de infravermelho (FTIR) para avaliação de alterações na sua estrutura química, ligações e grupos funcionais a fim de definir o impacto do método e das substâncias utilizadas na estrutura do material final, quando comparado à folha nativa. 


\section{MATERIAIS E MÉTODOS}

\subsection{Matéria prima utilizada e processo de modificação química}

A planta de escolha para esse estudo foi o espinafre, Spinacea Oleracea, da ordem dos cariofilales, família Chenopodiaceae, adquiridas em mercado local. Para tanto foram utilizadas folhas armazenadas em temperatura entre 5 e $7{ }^{\circ} \mathrm{C}$ antes do processamento. Os reagentes químicos utilizados foram hexano, dodecilsulfato de sódio (SDS), Triton X-100, hipoclorito de sódio, tampão fosfato salino (PBS) e água deionizada (DI).

O processamento químico foi dividido em dois momentos, um momento inicial onde as plantas foram submetidas a tratamento para remoção da cutícula presente na superfície das folhas, e o segundo momento, através de uso de detergentes iônicos e não-iônicos, sendo realizado tanto pelo método de imersão quanto pelo de perfusão. Cada ciclo teve duração média de 7 dias.

Os tratamentos (CUT) para remoção das cutículas consistiram em testar uma série de misturas de hexano $98 \%$ e solução tampão, em variados tempos de imersão, conforme mostrado na tabela 1.

Tabela 1: Experimento para remoção de cutícula de folhas vegetais por imersão

\begin{tabular}{l|l|c|c}
\hline EXPERIMENTO & \multicolumn{1}{|c|}{ SOLUÇÃO } & PH & TEMPO DEIMERSÃO \\
\hline CUT 1 & $1-$ Hexano 98\% & $5,0+0,1$ & 30 minutos \\
\hline \multirow{2}{*}{ CUT 2 } & $1-$ Hexano 98 \% & $5,0+0,1$ & 15 minutos \\
\cline { 2 - 4 } & $2-$ PBS & $7,0+0,1$ & 10 minutos \\
\hline CUT 3 & $1-$ Hexano 98\% + PBS $(*)$ & $5,7+0,2$ & 30 minutos \\
\hline CUT 4 & $1-$ Hexano 98\% + PBS $(*)$ & $7,0+0,1$ & 10 minutos \\
\hline
\end{tabular}

(*) Adição de tampão fosfato salino (PBS) até atingir o valor de $\mathrm{pH}$ pretendido.

Após a fase inicial de remoção da cutícula, grupos de folhas foram submetidos ao processamento químico por perfusão ou por imersão. O método de perfusão (PERF) das soluções através das folhas foi realizado por meio de cânula inserida no pecíolo e conectada à reservatório contendo as soluções de estudo e os processos de imersão (IME) foram realizado com utilização de recipiente de polietileno contendo as soluções. A tabela 2 descreve a matriz de experimentos dos protocolos utilizados. Ao final de todos esses processos, as folhas foram submetidas a lavagem com água deionizada estéril durante 48 horas. A estocagem das folhas foi feita em água deionizada em temperatura de $4_{ \pm} 2^{\circ} \mathrm{C}$.

Tabela 2: Experimento de degradação química na estrutura de folhas vegetais

\begin{tabular}{|c|c|c|c|}
\hline EXPERIMENTO & MÉTODO & SOLUÇÃO & $\begin{array}{l}\text { TEMPO DE } \\
\text { EXPOSIÇÃO }\end{array}$ \\
\hline \multirow{2}{*}{ PERF } & \multirow{2}{*}{ PERFUSÃO } & (1) - $10 \%(v / v)$ de SDS em água DI & 5 dias \\
\hline & & (2) $-0,1 \%(v / v)$ de Triton X-100 em água DI & 2 dias \\
\hline IME 1 & IMERSÃO & $10 \%(\mathrm{v} / \mathrm{v})$ de SDS em água DI & 5 dias \\
\hline IME 2 & IMERSÃO & $10 \%(\mathrm{v} / \mathrm{v})$ de SDS em água DI & 4 dias \\
\hline \multirow[b]{2}{*}{ IME 3} & \multirow[b]{2}{*}{ IMERSÃO } & $(1)-10 \%(v / v)$ de SDS em água DI & 4 dias \\
\hline & & \begin{tabular}{|l|}
$(2)-1 \%(v / v)$ de Triton X-100 em solução \\
$10 \%(\mathrm{v} / \mathrm{v})$ de hipoclorito de sódio em água DI \\
\end{tabular} & 2 dias \\
\hline \multirow{3}{*}{ IME 4} & \multirow{3}{*}{ IMERSÃO } & $(1)-10 \%(v / v)$ de SDS em água DI & 4 dias \\
\hline & & (2) - $1 \%(v / v)$ de Triton X-100 em água DI & 3 dias \\
\hline & & (3) - 5\% (v/v) de hipoclorito de sódio em água DI & 1 dia \\
\hline CONTROLE & \multicolumn{3}{|c|}{ FOLHA SEM NENHUM TIPO DE TRATAMENTO PRÉVIO } \\
\hline
\end{tabular}




\subsection{Ensaio de reticulação com glutaraldeído (GA)}

Amostras de folhas controle foram submetidas ao processo de reticulação através de imersão em solução de glutaraldeído $25 \%$ em água deionizada, diluída para concentração de $2 \%(\mathrm{~m} / \mathrm{v})$ e mantidas por período de 24 horas quando foram enxaguadas, sendo definidas como amostras CONTROLE-GA. Parte dessas amostras foi submetida ao processo químico conforme protocolo IME3, sendo definidas como IME3-GA.

\subsection{Ensaio de precipitação (SBF)}

Amostras de folhas CONTROLE e dos protocolos IME foram imersas em $10 \mathrm{ml}$ de solução de fluido corporal simulado (SBF) obtida de acordo com protocolo descrito por KOKUBO e TAKADAMA [7], nas seguintes concentrações de íons $\left(\mathrm{Na}^{+} 142,0 ; \mathrm{K}^{+} 5,0 ; \mathrm{Mg}^{2+} 1,5 ; \mathrm{Ca}^{2+} 2,5 ; \mathrm{Cl}^{-} 147,8 ; \mathrm{HCO}^{2-} 4,2 ; \mathrm{HPO}_{4}^{2-} 1,0\right.$; $\mathrm{SO}_{4}^{2-} 0,5 \mathrm{mM}$ ), iguais àquelas do plasma sanguíneo humano. As amostras imersas em SBF foram acondicionadas em estufa com circulação de ar, CIENLAB em temperatura aproximada de $37^{\circ} \mathrm{C}$, durante 21 dias. As amostras foram analisadas para os períodos de 0,7 e 21 dias, com renovação da solução a cada 7 dias. Após completo a prazo de imersão, as amostras foram secas em dessecador para posterior caracterização. A tabela 3 apresenta a matriz de experimentos das amostras submetidas ao ensaio de imersão em SBF

Tabela 3: Matriz de experimento de amostras submetidas ao ensaio em SBF

\begin{tabular}{|c|c|c|}
\hline AMOSTRA & $\begin{array}{l}\text { PROTOCOLO DE } \\
\text { DEGRADAÇÃO }\end{array}$ & $\begin{array}{c}\text { TEMPO DE IMERSÃO EM } \\
\text { SBF (DIAS) }\end{array}$ \\
\hline CONTROLE & \multirow{3}{*}{ NENHUM } & 0 \\
\hline CONTR-SBF-7 & & 7 \\
\hline CONTR-SBF-21 & & 21 \\
\hline IME & \multirow{3}{*}{ IME } & 0 \\
\hline IME-SBF-7 & & 7 \\
\hline IME-SBF-21 & & 21 \\
\hline
\end{tabular}

\subsection{Caracterização}

\subsubsection{Microscopia eletrônica de varredura (MEV) e Espectroscopia de Energia Dispersiva (EDS)}

Amostras das folhas nativas e tratadas quimicamente foram resfriadas até a temperatura de $0^{\circ} \mathrm{C}$ e mantida por período de 12 horas. Posteriormente as amostras foram submetidas ao processo de liofilização durante 8 horas, realizado em equipamento modelo Terroni LT600. Em seguida as amostras foram, cortadas e fixadas em porta amostra com fita dupla face. Para amostras analisadas no MEV foi procedida metalização com fina camada de ouro por sputtering utilizando o equipamento Quick Coater Sanyu Eléctron, para tornar suas superfícies condutoras para o feixe de elétrons. As caracterizações de MEV/EDS foram feitas com a utilização do equipamento marca Shimadzu modelo Superscan SSX-550, operados com voltagem de aceleração entre 5 a $15 \mathrm{kV}$, sendo obtidas imagens de elétrons secundários.

\subsubsection{Espectroscopia de absorção na região de infravermelho (FTIR)}

As amostras foram analisadas no espectrofotômetro da Shimadzu Corporation, modelo IRPrestige-21, equipado com transformada de Fourier, FTIR-8400S e acessório ATR DuraSampl IR II, com cristal de ZnSe. A técnica utilizada foi de 68 varreduras entre 4000 e $500 \mathrm{~cm}^{-1}$, com resolução de $4 \mathrm{~cm}^{-1}$ e intervalo de $2 \mathrm{~cm}^{-1}$.

\subsubsection{Análise Termogravimétrica (TGA) e Análise Térmica Diferencial (DTA)}

As amostras foram analisadas em equipamento SII EXSTAR, modelo TG/DTA 7200, em atmosfera dinâmica de nitrogênio, com vazão de $50 \mathrm{~mL} \cdot \mathrm{min}^{-1}$ e taxa de aquecimento à razão de $10^{\circ} \mathrm{C} \mathrm{min}^{-1}$ para a TGA e de $2^{\circ} \mathrm{C}$ $\min ^{-1}$ para a DTA, em suporte de alumina, temperatura compreendida entre 10 e $900^{\circ} \mathrm{C}$ para a TGA e de 30 a $500^{\circ} \mathrm{C}$ para a DSC, cortadas em filmes ou membranas finas, em pedaços com área suficiente para cobrir a superfície interna do cadinho $\left(\sim 4 \mathrm{~mm}^{2}\right)$ e colocados em camadas totalizando a massa aproximada de $10 \mathrm{mg}$. 


\section{RESULTADOS}

A descrição qualitativa de análise visual e de resistência à manipulação de amostras submetidas aos vários testes para remoção da cutícula das folhas estudas é apresentada na tabela 4.

Tabela 4: Aspecto qualitativo de amostras submetidas à protocolos de remoção da cutícula (CUT)

\begin{tabular}{l|l|c}
\hline EXPERIMENTO & \multicolumn{1}{|c}{ ASPECTO VISUAL } & RESISTENCIA À MANIPULAÇÃo \\
\hline CUT 1 & Alteração marcante na textura & Baixa \\
\hline CUT 2 & Alteração marcante na textura & Baixa \\
\hline CUT 3 & Alteração menos evidente na textura & Próxima ària resistência inicial \\
\hline CUT 4 & $\begin{array}{l}\text { Remoção da cutícula sem alteração } \\
\text { expressiva na textura }\end{array}$
\end{tabular}

A figura 1 mostra o aspecto de amostras submetidas aos processos de tratamento químico descritos na tabela 2. Amostra da figura 1A, referente a folha CONTROLE, mostra pigmentação mais escura e aspecto mais estruturado. A imagem da figura 1B que é relacionada ao tratamento PERF mostra perda discreta de pigmentação e evidencia os ductos principais, caracterizado por um maior contraste das folhas em relação aos seus vasos. A amostra submetida ao protocolo IME3, indicada na figura 1C, mostra a folha preservada e despigmentada em sua totalidade. A figura 1D, de folhas tratadas pelo protocolo IME4, mostra a remoção de grande parte do pigmento da folha com alguns resquícios de pigmento visíveis em várias regiões da folha.

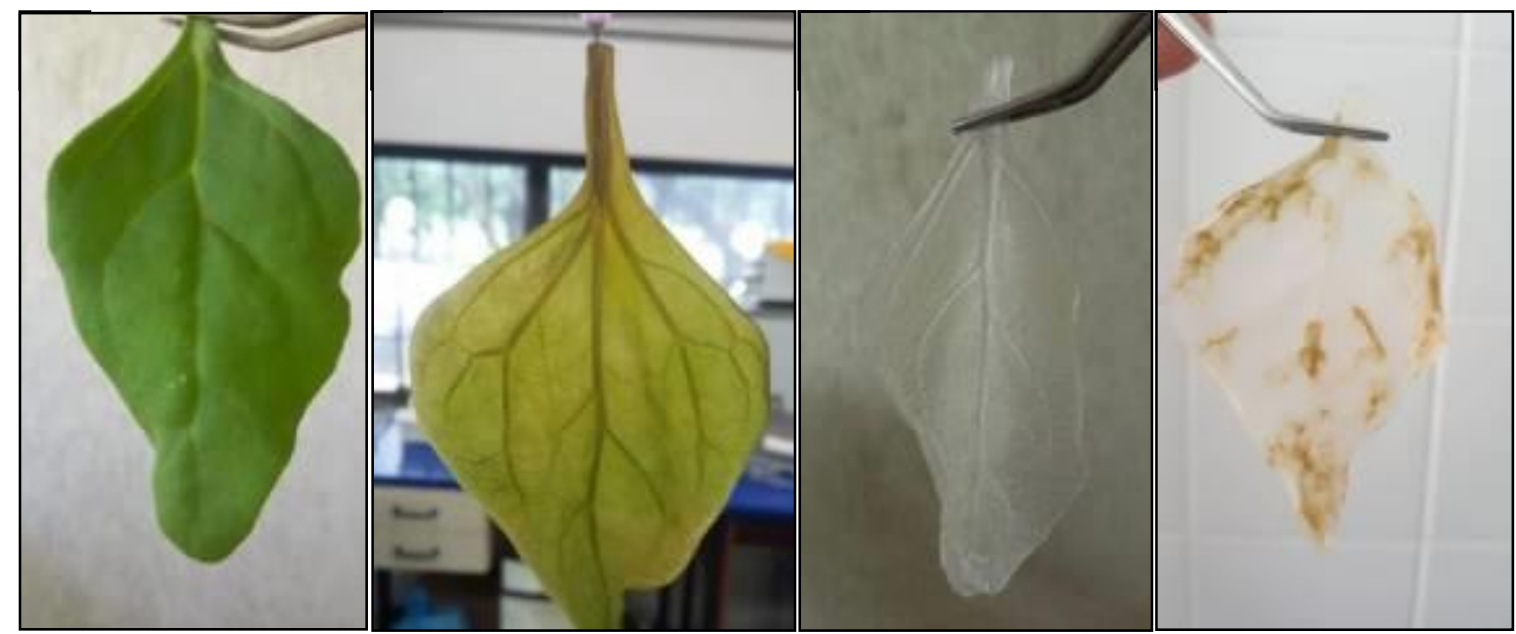

Figura 1: Imagem fotográfica de amostras de folhas de espinafre (A) CONTROLE e submetidas aos protocolos (B) PERF, (C) IME3 e (D) IME4.

A tabela 5 corresponde aos valores de porcentagem atômica obtidos em espectroscopia de energia de elétrons de amostras de folhas CONTROLE e folhas submetidas ao protocolo IME3. Na análise foram detectados picos referentes aos elementos carbono, oxigênio, magnésio, sódio e cloro, onde foi verificada a presença, nas folhas CONTROLE, de altas concentrações de carbono e oxigênio, como é de se esperar para componentes de folhas vegetais. Além desses elementos, foi verificada presença de traços de magnésio, que é característico em cloroplastos. As folhas tratadas por IME3 são verificados os mesmos elementos, com exceção para o magnésio que não foi detectado por EDS para essas amostras. 
Tabela 5: EDS de folhas CONTROLE e submetidas ao protocolo IME4.

\begin{tabular}{l|c|c|c|c|c}
\hline \multirow{2}{*}{ AMOSTRA } & \multicolumn{5}{c}{ ASPECTO ELEMENTO QUÍMICO (\% ATÔMICA) } \\
\hline & C & $\mathbf{0}$ & $\mathbf{M g}$ & $\mathbf{N a}$ & $\mathbf{C l}$ \\
\hline CONTROLE & 60,9 & 30,0 & 0,1 & - & - \\
\hline IME3 & 70,2 & 26,0 & - & 1,4 & 2,4 \\
\hline
\end{tabular}

A figura 2 exibe imagens obtidas por MEV da superfície e da rede vascular de folhas CONTROLE e de folhas tratadas seguindo o protocolo IME3. Na figura 2A é mostrada folha CONTROLE, com destaque para a presença de algumas estruturas como célula vegetal e estômatos, assinaladas na imagem. Na figura 2B, não estão mais presentes as estruturas identificadas em $2 \mathrm{~A}$, como células vegetais, além disso fica sugestiva a presença de estrutura da matriz extracelular vegetal com presença dos feixes de celulose. As imagens dos ductos das amostras $2 \mathrm{~A}$ e $2 \mathrm{~B}$, representadas em $2 \mathrm{C}$ e $2 \mathrm{D}$, respectivamente, sugerem que mesmo após o tratamento químico os ductos se mostraram presentes.

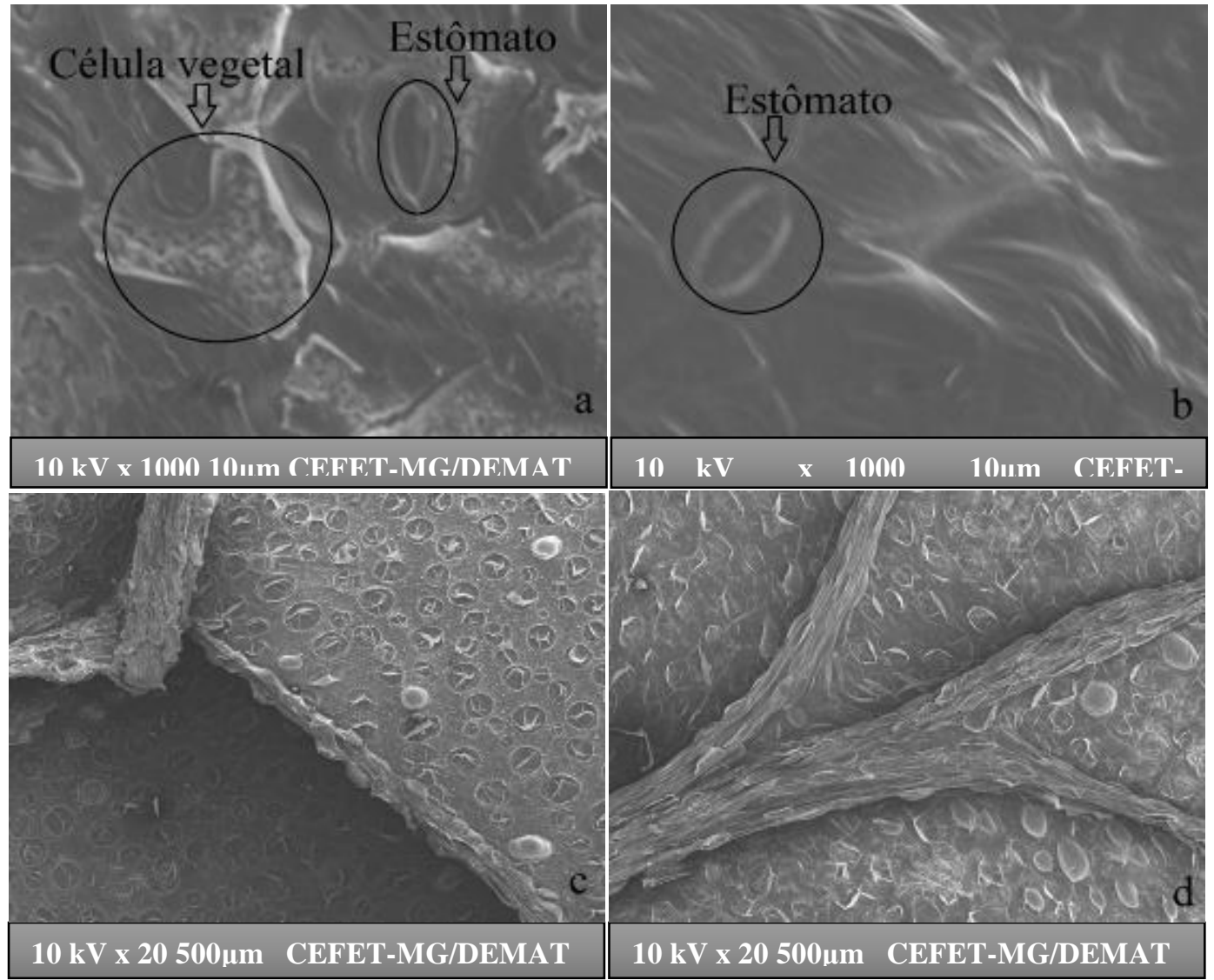

Figura 2: Imagem de MEV de (A) folha CONTROLE. (B) folha submetida ao protocolo IME3, (C) e (D) mostrando rede vascular de $(\mathrm{A})$ e $(\mathrm{B})$, respectivamente.

O comportamento das amostras, quando aquecidas e submetidas à TGA/DTA, é apresentado na figura 3 é foi dividido em três estágios principais para amostras de folhas nativas e em quatro estágios principais para amostras de folhas do experimento IME3.

As temperaturas foram definidas para o fim do primeiro estágio, com base na mudança das inclinações verificadas pelos gráficos de termogravimetria, definidos em $142^{\circ} \mathrm{C}$ para amostra CONTROLE e em $117^{\circ} \mathrm{C}$ para amostra IME3. O primeiro estágio da amostra CONTROLE (30 a $142^{\circ} \mathrm{C}$ ) apresentou perda na faixa de $94,3 \%$ da massa, enquanto para amostra IME3 $\left(30\right.$ à $\left.117^{\circ} \mathrm{C}\right) \mathrm{o}$ valor foi de $92,7 \%$ de perda de massa. 


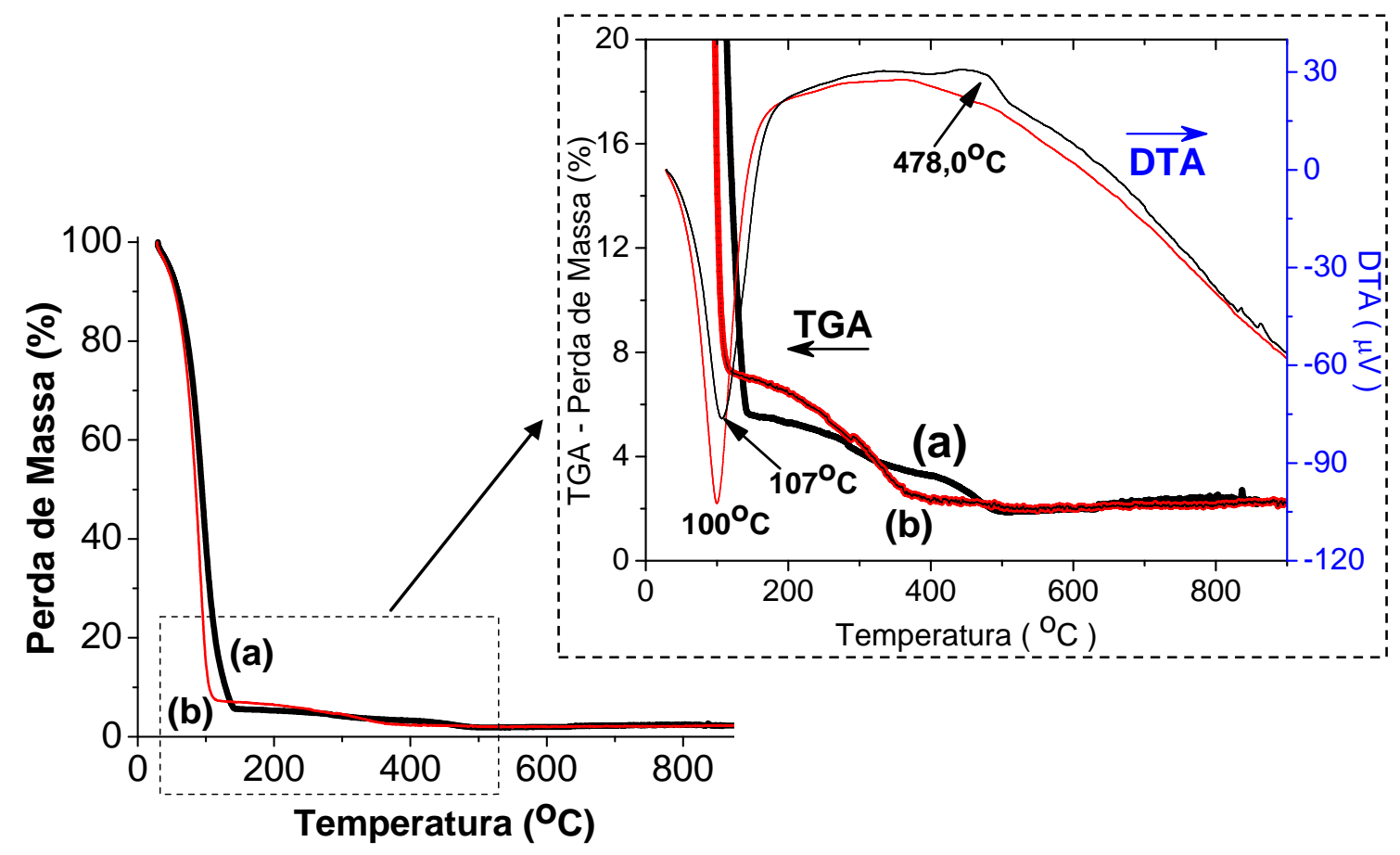

Figura 3: Curvas termogravimétricas das amostras (a) CONTROLE e (b) IME3. Detalhe mostrando TG associado à DTA.

Analisando os resultados obtidos por FTIR, verificamos que as bandas posicionadas em 3330, $2921 \mathrm{e}$ $2850 \mathrm{~cm}^{-1}$ estão presentes em amostras CONTROLE e IME3. A banda em $3330 \mathrm{~cm}^{-1}$ pode ser associada à grupos $\mathrm{OH}$ ou à água adsorvida, e se mostra com elevada intensidade em ambas amostras, entretanto para amostras IME3 foi observada redução na sua intensidade. Outra banda posicionada em $1636 \mathrm{~cm}^{-1}$, que também pode ser associada ao grupo $\mathrm{OH}$ da água apresentou redução para amostras submetidas ao IME3 além das bandas posicionadas em 2918 e $2849 \mathrm{~cm}^{-1}$, que podem ser associadas aos grupos $\mathrm{CH}_{2}$ e $\mathrm{CH}_{3}$.

Ainda na análise do FTIR, verificamos uma série de bandas posicionadas entre 1640 e $1000 \mathrm{~cm}^{-1}$ que demonstraram clara redução nas suas intensidades para amostras IME3, quando comparadas com as folhas CONTROLE e algumas bandas que não estavam presentes para a folha CONTROLE e aparecem no FTIR de amostras IME3, como as observadas em $2334 \mathrm{~cm}^{-1}$ e em $1995 \mathrm{~cm}^{-1}$.

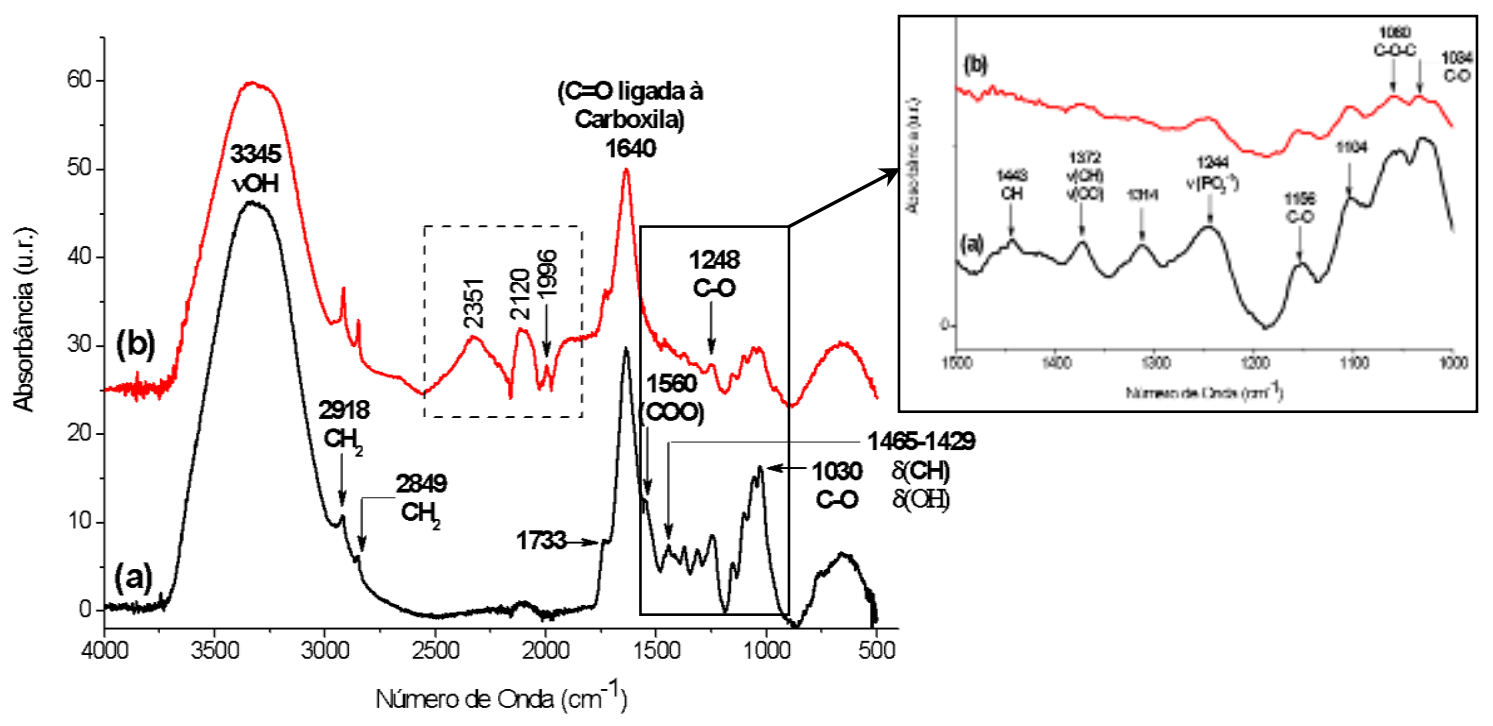

Figura 4: Análise FTIR de amostras (a) CONTROLE e (b) IME3. Detalhe indica ampliação da região compreendida entre 1000 e $1500 \mathrm{~cm}^{-1}$ 
Além dos picos em comum ao gráfico da figura 4, as amostras CONTROLE-GA e IME3-GA da figura 5 apresentam destaque para a presença das bandas posicionadas em 2918 e $2849 \mathrm{~cm}^{-1}$, que podem ser associadas aos grupos $\mathrm{CH}_{2}$ e $\mathrm{CH}_{3}$ e se mostraram mais evidentes nas amostras submetidas ao tratamento IME3 seguidos por reticulação.

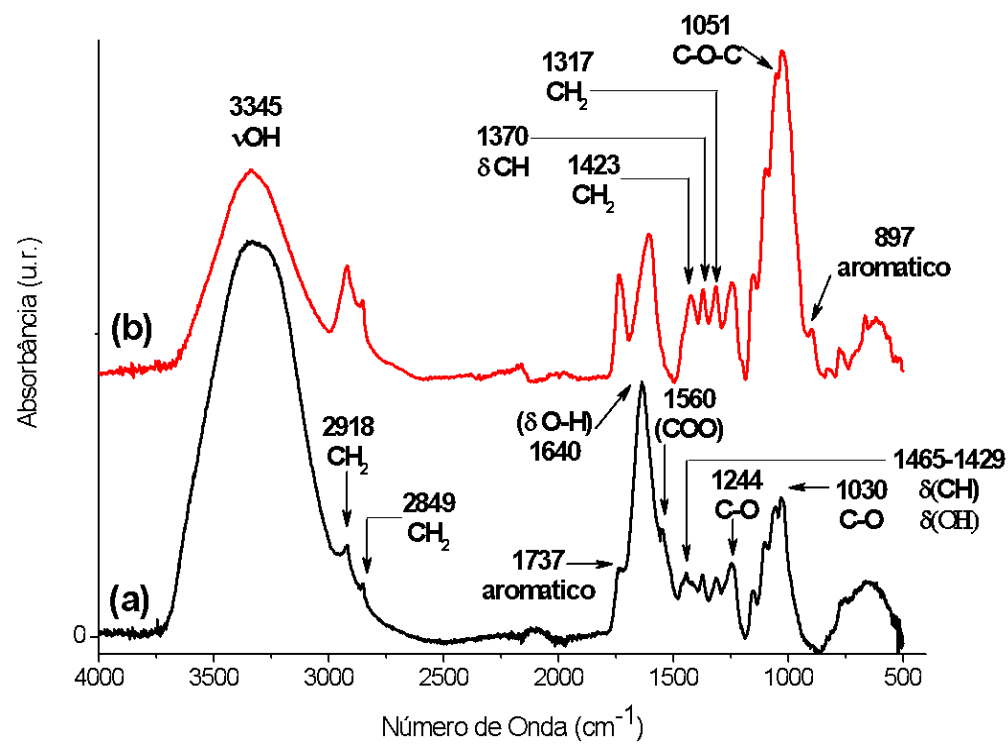

Figura 5: Análise FTIR de amostras (a) CONTROLE e (b) IME3-GA.

Algumas bandas associadas à grupos químicos relacionados aos conteúdos celulares que tiveram redução na sua intensidade, como é o caso de $1244 \mathrm{~cm}^{-1}$ que pode ser associado a grupos $\mathrm{PO}_{2}^{-1}$ de ácidos nucléicos e $1640 \mathrm{~cm}^{-1}$, apresentaram menor intensidade em IME3-GA e IME3 seca respectivamente, sugerindo que a reticulação pode ter influência direta na facilitação de enxague e saída de debris celulares.
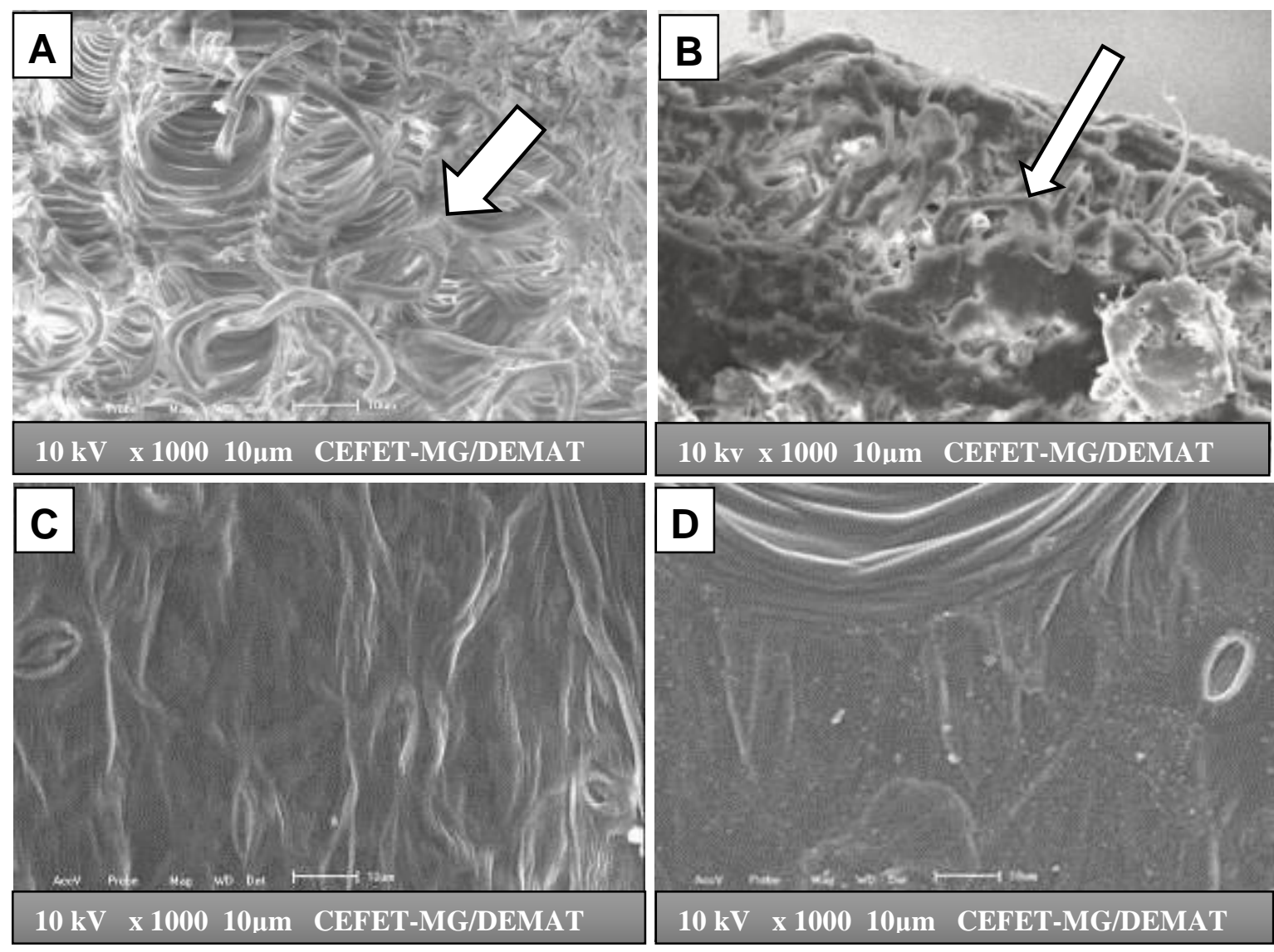
Figura 6: Imagens do MEV mostrando seção transversal do ducto principal de amostras: (A) CONTROLE-GA e (B) IME3-GA. Setas mostrando detalhe de anéis da estrutura dos ductos. Em (C) e (D) são mostradas vistas da superfície das amostras (A) e (B), respectivamente.

A figura 6A é uma vista da seção transversal de ducto de amostras CONTROLE-GA. Nessa imagem podemos observar o tecido de sustentação do ducto envolvendo os vários canalículos que formam a rede vascular vegetal. Na amostra IME3-GA da figura $6 \mathrm{~B}$, as imagens obtidas se mostram mais obliquas em relação à seção transversal e indicam as fibras dos ductos sem a mesma organização das folhas CONTROLE, entretanto podemos ver na região da seta algumas estruturas em forma de anéis, sendo parte deles rompida, além da presença de partículas no interior desses anéis.

A figura 7 corresponde à análise de FTIR das amostras (a) IME3, (b) IME3-SBF-7 e (c) IME3-SBF-21, onde podemos observar que os mesmos picos aparecem para todas as amostras, variando apenas a sua intensidade. Para esta análise, todas as amostras foram secas. O pico $3345 \mathrm{~cm}^{-1} \mathrm{em}$ IME3 está relacionado a estiramento de ligação $\mathrm{OH}$ e é praticamente imperceptível nas demais amostras. $\mathrm{O}$ pico $3182 \mathrm{~cm}^{-1}$ aparece nas amostras IME3-SBF-7 e IME3-SBF-21, está relacionado a estiramento $\mathrm{CH}$ da estrutura da celulose. $\mathrm{O}$ pico $2918 \mathrm{~cm}^{-1}$, que em IME3 aparece vibrando em alta intensidade, apresentou diminuição expressiva com o aumento do tempo de exposição ao SBF, apresentando menor intensidade em IME3-SBF-21.

$\mathrm{O}$ pico $1736 \mathrm{~cm}^{-1}$ está presente de maneira expressiva somente em IME3 e não aparece nas demais, essa região está relacionada à estiramento $\mathrm{C}=\mathrm{O}$ geralmente associada à lignina e hemicelulose. A diminuição da intensidade do pico $1036 \mathrm{~cm}^{-1}$ das amostras com SBF em relação à IME3, sugere que houve ligação de grupo fosfato nas cadeias que se romperam durante o processamento para decelularização. A presença do grupo fosfato $\left(\mathrm{PO}_{4}{ }^{3-}\right)$ está fortemente relacionada à vibração dos picos $662 \mathrm{~cm}^{-1} \mathrm{e} 596 \mathrm{~cm}^{-1}$, mais intenso na amostra IME3-SBF-21

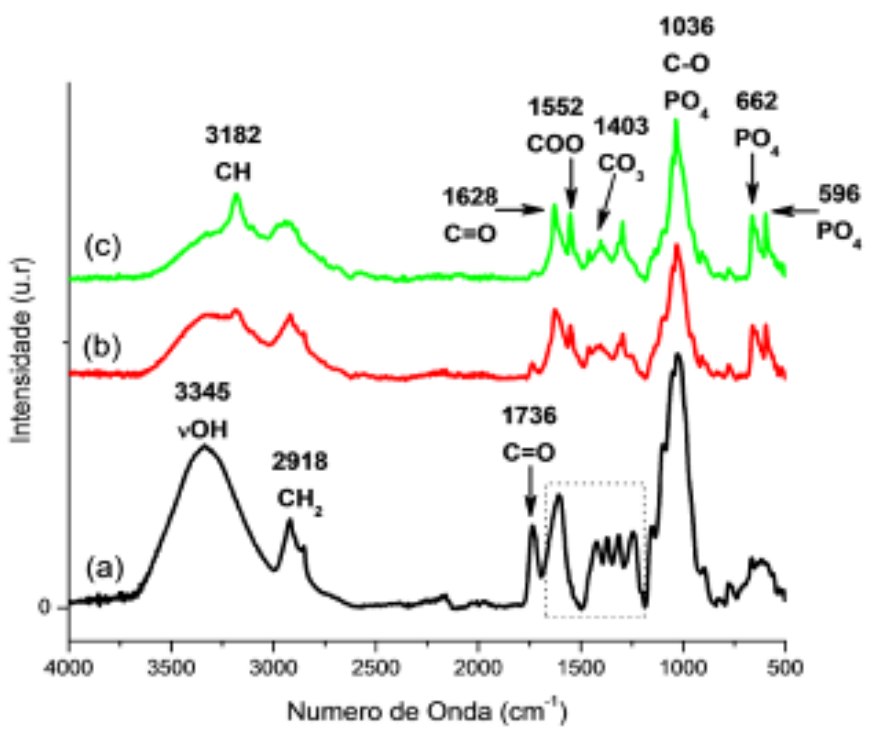

Figura 7: Análise de FTIR de (a) IME3, (b) IME3-SBF-7 e (c) IME3-SBF-21

Na imagem da figura 8A é mostrada folha CONTROLE com superfície de aspecto irregular, sendo que após o tratamento pelo protocolo IME3 é observado um aspecto com ondulações mais discretas, conforme mostrado na figura 8B. Nas amostras referentes ao ensaio de imersão em SBF, é possível observar na figura $8 \mathrm{C}$, que para amostra imersa por 7 dias, predominou fino precipitado disperso por todo o campo. Para amostra imersa por período de 21 dias, indicada na figura 8D, a seta destaca uma área de maior concentração de precipitado, cujo EDS (não mostrado) indicou presença de cálcio, fósforo, cloro, sódio e magnésio. As amostras de CONTROLE-SBF-21 sofreram degradação intensa impossibilitando a caracterização. 

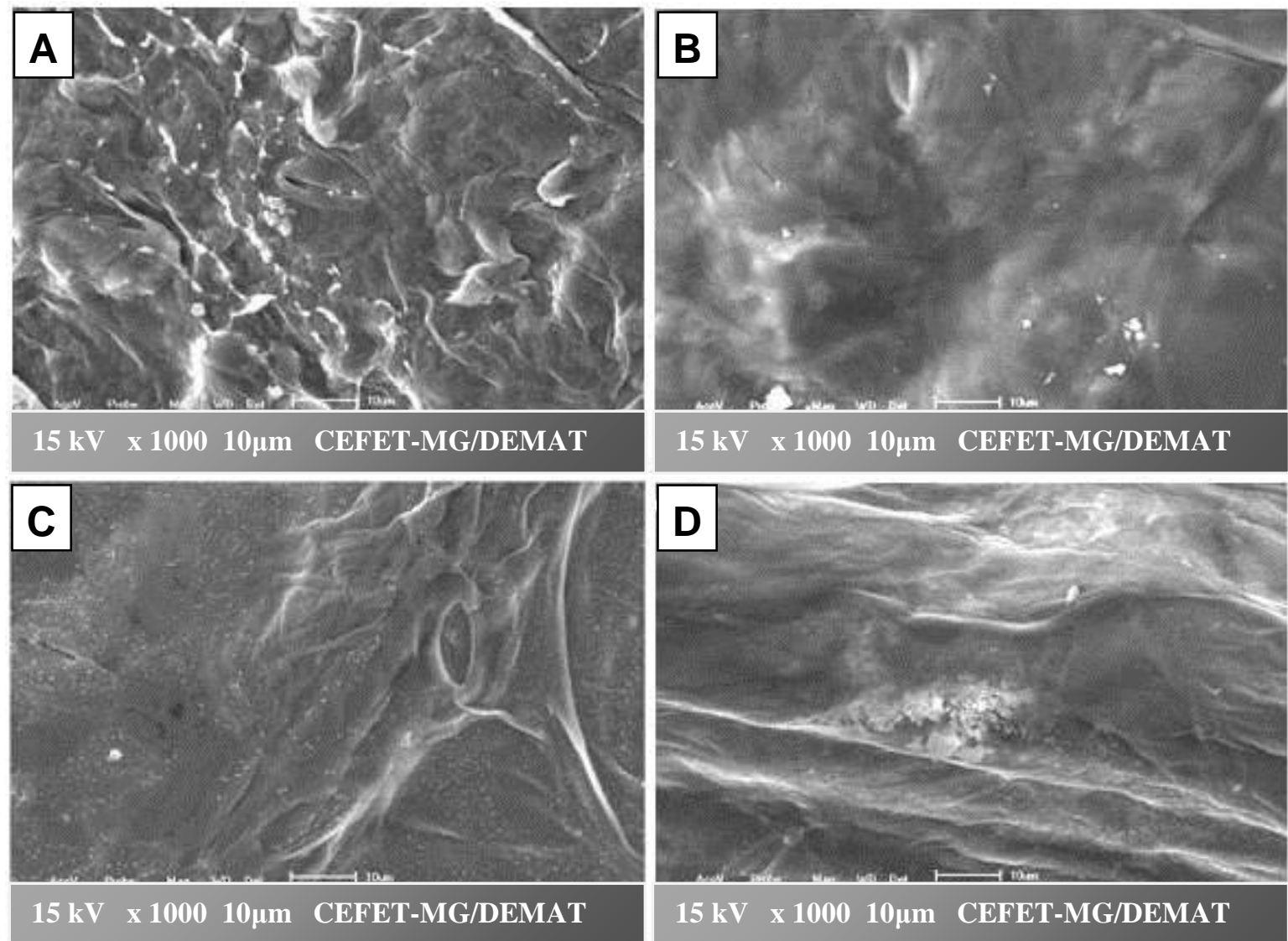

Figura 8: Imagens do MEV de amostras (a) CONTROLE e amostras submetidas ao protocolo IME3 seguidas por (b) 0; (c) 7 e (d) 21 dias de imersão em SBF.

\section{DISCUSSÃo}

Folhas vegetais apresentam externamente uma cobertura de cera, denominada cutícula vegetal, cuja função é evitar perda de água e proteger a folha contra infecções e traumas mecânicos [12]. Nesse trabalho a primeira etapa consistiu em utilizar hexano como solvente orgânico para promover a retirada dessa cutícula, entretanto a ação desse reagente para os tempos testados resultou em diminuição crítica na resistência da folha, conforme indicado na tabela 4, bem como degradação excessiva. Para tanto foi utilizado PBS para tamponar o sistema, bem como o ajuste dos tempos da reação, onde foi obtida a melhor condição para a mistura de hexano com PBS, com valor de $\mathrm{pH}$ igual à 7,0; sendo essa metodologia definida como padrão para todas as amostras submetidas aos demais protocolos adotados.

A etapa seguinte consistiu em utilizar detergentes iônicos e não-iônicos, buscando remover os conteúdos das células vegetais, sendo realizado tanto o método de perfusão quanto de imersão, seguindo os protocolos indicados na tabela 2. Os resultados de perfusão das soluções apresentaram elevada resistência à entrada do líquido na rede vascular nas folhas, degradação do pecíolo, bem como despigmentação limitada, conforme mostrado na figura 1B. Já os resultados obtidos por imersão variaram conforme os tempos de imersão e as soluçães utilizadas, sendo que a utilização de Triton X juntamente com hipoclorito resultou em remoção de maior quantidade de pigmento, conforme mostra a comparação entre as figuras $2 \mathrm{C}$ e $2 \mathrm{D}$, isso em menor período de imersão e com amostras IME3 apresentando maior resistência à manipulação. Dessa forma foi realizada extensa caracterização de folhas CONTROLE comparadas com amostras obtidas pelo protocolo IME3, que obtiveram melhores características de remoção da pigmentação e de resistência à manipulação.

Análise de EDS indicada na tabela 4 identificou presença de carbono, oxigênio e magnésio nas amostras CONTROLE, elementos presentes nas células e necessários ao processo de fotossíntese. Nos valores de amostra IME3, aparecem $\mathrm{C}$ e $\mathrm{O}$, o que pode demonstrar a manutenção da estrutura molecular, ausência de $\mathrm{Mg}$, sugestivo da remoção de conteúdos celulares, além de $\mathrm{Na}$ e $\mathrm{Cl}$ que podem representar resíduos das soluções de PBS, SDS, Triton X-100 e NaOCl utilizadas.

Com relação à ocorrência de sódio no EDS, destacamos que esse elemento faz parte de alguns sistemas utilizados em biomateriais, como vidros bioativos [13] e alginato de sódio [14], estando presente no plasma 
sanguíneo [7] e desempenhado papel fundamental no metabolismo ósseo, onde se observa risco aumentado de fratura em concentrações plasmáticas inferiores à 135 mmol.L-1) [15].

Outro resíduo associado aos reagentes utilizados é caracterizado pelo cloro, que também faz parte dos componentes do plasma sanguíneo, cuja concentração varia entre 95 e $107 \mathrm{mmol} . \mathrm{L}^{-1}$ [7]. Além disso, segundo HENCH e WILSON [16] o conteúdo de cloro no osso natural é de $0,13 \%$ (p/p). Dessa forma, considerando que o valor de 2,4 por cento de cloro obtido no EDS foi associado à massa seca da membrana, cuja hidratação é próxima de $93 \%$, o peso do cloro referente à membrana hidratada passa a ser inferior à $0,18 \%$ $(\mathrm{p} / \mathrm{p})$, valor mais próximo daquele observado no osso, ainda mais tomando por base o EDS como uma análise pontual e semiquantitativa.

Apesar de o cloro detectado poder ser associado ao $\mathrm{NaOCl}$ [17], a literatura apresenta trabalhos de avaliação de citotoxicidade, que indicam apenas a ocorrência de parada transitória do crescimento celular, onde as células parecem ser capazes de recuperar a viabilidade após $24 \mathrm{~h}$ de incubação, em concentrações de intermediárias a baixas de $\mathrm{NaOCl}(0,025-0,0075 \%)$. Além disso, a evaporação de ácido hipocloroso, em soluções de $\mathrm{NaOCl}$ em água destilada, é dependente do tempo, sendo produzido nas primeiras 4 horas e com diminuição no efeito citotóxico, à medida que o tempo de exposição ao hipoclorito é prolongado $[18,19]$.

Essas observações são aspectos a serem considerados para a otimização do protocolo de decelularização, de maneira a diminuir concentrações desses resíduos na estrutura da folha para minimizar a possibilidade de reações indesejáveis, quando da sua aplicação em sistemas biológicos [20, 21].

Os aspectos morfológicos de amostras CONTROLE e IME3 obtidos nas imagens de MEV da figura 2 exibem na figura $2 \mathrm{~A}$ imagens da superfície com células vegetais epidérmicas de estrutura granulada densa, não visualizadas na figura $2 \mathrm{~B}$. Já os estômatos mantiveram sua estrutura original em ambas imagens. Além disso, a figura 2B mostra estruturas alongadas sugestivas de componentes da matriz extracelular vegetal, representada por feixes de celulose, sem rupturas ou pontos de fratura na matriz remanescente, dando indicativo de manutenção da sua integridade. A figuras $2 \mathrm{C}$ e $2 \mathrm{D}$ apresentam aspecto importante na medida que indicam integridade dos vasos principais da folha vegetal estudada.

Ainda que o objetivo deste trabalho seja avaliação da estrutura de celulose remanescente após o processamento, o indicativo de remoção celular é um resultado relevante uma vez que, a remoção das células vegetais é fator importante para biocompatibilidade, evitando possíveis reações de corpo estranho, bem como para não interferir no processo futuro de reparação tecidual. Os estômatos, estruturas responsáveis pela transpiração das folhas, permaneceram íntegros, o que pode ser de grande valia para obtermos um material permeável, facilitando trocas com o meio externo, tanto importando nutrientes quanto exportando metabólito.

A faixa inicial de perda de massa, obtida a partir do gráfico de TGA da figura 3, tanto para amostras CONTROLE quanto IME3, pode ser amplamente relacionada à perda de água. Dessa forma os gráficos indicam valores de massa seca iguais à $6 \%$ para CONTROLE e 7\% para IME3. Utilizando os dados do mesmo gráfico, recalculados de forma a considerar os valores de massa seca como cem por cento de massa das amostras, temos que a perda para amostra CONTROLE é $67 \%$ até a temperatura de $500^{\circ} \mathrm{C}$ e os resíduos correspondem à 33\% da massa seca. Para amostra IME3 a perda de massa é em torno de $72 \%$ e os resíduos correspondem à $28 \%$ da massa seca. Sendo assim, tais resultados dão indicativo que a perda de massa é maior para amostras IME3, na medida que os valores menores de resíduos sugerem que o tratamento tenha conseguido remover parte dos componentes da folha.

Importante também é verificar a redução das temperaturas dos picos endotérmicas de $107^{\circ} \mathrm{C}$ nas amostras CONTROLE para $100^{\circ} \mathrm{C}$ em IME3, indicando facilidade de remoção da água em estrutura mais degradada após o tratamento químico. Além de pico exotérmico em torno de $478^{\circ} \mathrm{C}$ observado em CONTROLE e ausente em IME3, sugestivo da efetividade na remoção de componentes das folhas durante os tratamentos. Comparando com dados da literatura verificamos que os valores obtidos na análise termogravimétrica correspondentes à umidade foram de $94,3 \%$ e para as cinzas foram de 1,9\%, muito próximos daqueles verificados por STORCK et al. [25] que indicaram em tabela de composição centesimal das partes nobres de espinafre, correspondendo às principais estruturas utilizadas no consumo humano, caracterizado principalmente pelas folhas, valores de umidade iguais a $94,0 \%$ e cinzas iguais a $1,2 \%$.

Os resultados obtidos pelo FTIR da figura 4 mostraram alterações importantes, com redução da banda de OH para amostras IME3, em $3330 \mathrm{~cm}^{-1}$, que podem sugerir remoção de parte da estrutura da folha que mantinha ligação com moléculas de água ou quebrado parte da celulose, com diminuição da sua massa após o processamento $[10,11]$. Na mesma figura verificamos também alterações entre $1500 \mathrm{e} 1000 \mathrm{~cm}^{-1}$, como as reduções de intensidade em amostras IME3 das bandas $1443 \mathrm{~cm}^{-1}$ do estiramento C-H, a banda $1372 \mathrm{~cm}^{-1}$ associada ao dobramento $\mathrm{CH}$ da hemicelulose, a banda $1059 \mathrm{~cm}^{-1}$ do estiramento C-O e a banda $1030 \mathrm{~cm}^{-1}$ do estiramento $\mathrm{C}-\mathrm{OH}$, que podem ser associadas a outros carboidratos da celulose [10, 12, 23, 24]. Além disso, algumas bandas associadas à grupos químicos relacionados aos conteúdos celulares que tiveram redução na sua intensidade, como é o caso de $1244 \mathrm{~cm}^{-1}$ que pode ser associado a grupos $\mathrm{PO}_{2}{ }^{-1}$ de ácidos nucléicos e a banda $1059 \mathrm{~cm}^{-1}$ que pode ser associada à $\mathrm{PO}_{2}^{-1}$ de fosfodiéster e desoxirribose de ácidos nucléico [23]. Dessa forma esses resultados indicaram vibrações de grupos presentes na estrutura da folha 
composta por celulose que apresenta vibrações antes e após o tratamento, sugestivo da manutenção da estrutura da folha. Além disso, algumas bandas foram observadas antes e após o tratamento, mas com redução para folhas tratadas, sugestivas de degradação de parte da estrutura além das reduções de conteúdos celulares.

Algumas caracterizações foram realizadas em folhas reticuladas com glutaraldeído e mostraram que a utilização desse agente alterou sobremaneira a estrutura das folhas, onde o FTIR da figura 5 mostra que amostras reticuladas apresentaram, após secagem em liofilizador, predomínio dos principais modos de vibração da celulose com redução dos grupos $\mathrm{OH}$ em 3500 e $1640 \mathrm{~cm}^{-1}$ e enorme destaque dos vários grupos associados à estrutura cíclica da celulose entre 1500 e $1000 \mathrm{~cm}^{-1}[12,23]$.

Nas imagens de MEV das amostras reticuladas, pode ser verificado que a estrutura circular dos canalículos e fibras de celulose são evidenciadas e sugerem que a estrutura obtida após reticulação preservou a morfologia, mesmo após a preparação das amostras para a execução dessa técnica de caracterização morfológica. Em relação às amostras IME3-GA foi verificada a presença de anéis da estrutura radicular da folha, entretanto essa estrutura se mostrou menos definida, podendo indicar degradação ocorrida durante o tratamento IME3 ou durante a preparação da amostra, seja pelo corte da seção, seja pela liofilização. Fato é que a preparação das amostras para a caracterização morfológica foi mais eficiente nas amostras reticuladas que na análise da superfície apresentou amostras CONTROLE-GA com fibras mais evidentes com uma textura mais aparente, diferente das amostras IME3-GA que apresentaram superfície mais plana, com perfil mais discreto das fibras e particulado fino precipitado sobre toda a superfície. Para tecidos duros como os ossos, é necessário que haja um equilíbrio entre a degradação das matrizes de reparação e sua resistência mecânica, onde essas matrizes devem possuir propriedades mecânicas adequadas capazes de suportar às forças de tração e compressão, bem como possuir tempo de biodegradação mínimo de 2 a 3 meses, tempo médio de reparação para esse tecido [9].

Os espectros de FTIR e as imagens de MEV das amostras submetidas à ensaio de imersão em SBF demonstraram afinidade do material à precipitação de fosfato tanto nas amostras CONTROLE-SBF-7 quanto nas amostras IME3-SBF-7 e IME3-SBF-21, mais pronunciada nas duas últimas, demonstrando maior afinidade do material tratado na formação da camada de fosfato, sendo sugestivo se tratar de camada de fosfato de cálcio, na medida que análise de EDS indicou presença de cálcio na superfície. Essa característica se mostra relevante para uma matriz cujo objetivo é a aplicação para tecido ósseo. Amostras CONTROLESBF-21 apresentaram degradação, por isso não foram caracterizadas morfologicamente, dessa forma pode ser destacado o tratamento químico de amostras IME3 que preservou as folhas por maior período de tempo, fato que pode estar relacionado à algum dos reagentes utilizados que tenha atuado eliminando bactérias e outros microrganismos e aumentando o tempo de conservação do material submetido a processo de decelularização.

\section{CONCLUSÃO}

Considerando a análise morfológica verificamos que o aspecto macroscópico indicou que o tratamento químico com os sabões utilizados foi mais eficiente em protocolos utilizando o método de imersão, onde foi verificada redução significativa da pigmentação e manutenção do sistema vascular das folhas. As análises das imagens obtidas por MEV sugerem que as estruturas celulares foram removidas, mesmo que parcialmente e que a matriz polimérica foi modificada, mas sem alteração estrutural significativa. Dados esses corroborados por análise térmica e de FTIR. A utilização de agente reticulante auxiliou nas caracterizações morfológicas e se mostrou uma alternativa para incrementar a resistência à manipulação das folhas à degradação promovida pelos tratamentos químicos com os sabões utilizados. Os ensaios de imersão em SBF indicaram que as matrizes tratadas com os sabões ampliaram o seu tempo de conservação em meio de simulação e apresentaram precipitados de fosfatos de cálcio na sua estrutura, onde pode-se concluir que o protocolo utilizado para tecido vegetal se apresenta como uma opção viável a desenvolvimento de matrizes pré vascularizadas para reparação óssea.

\section{AGRADECIMENTOS}

Ao CEFET-MG, Departamento de Engenharia de Materiais e Laboratório de Bioengenharia da UFMG pelo uso da infraestrutura. À Gustavo Castilho Dias pelo auxílio no laboratório.

\section{BIBLIOGRAFIA}

[1] BELADI, F., SABER-SAMANDARI, S., "Cellular compatibility of nanocomposite scaffolds based on hydroxyapatite entrapped in cellulose network for bone repair,” Mater. Sci. Eng. C, v. 75, pp. 385-392, 2017.

[2] LOPES, D., MARTINS-CRUZ, C., OLIVEIRA, M.B., et al., "Bone physiology as inspiration for tissue regenerative therapies,” Biomaterials, vol. 185, no. September, pp. 240-275, 2018. 
[3] FERRETTI, M., CONCETTA, MATTIOLI-BELMONTE, "Periosteum derived stem cells for regenerative medicine proposals: Boosting current knowledge," World J. Stem Cells, v. 6, n. 3, pp. 266-277, 2014.

[4] O'BRIEN, F.J. “Biomaterials \& scaffolds for tissue engineering," Mater. Today, v. 14, n. 3, pp. 88-95, 2011.

[5] ARAÚJO JÚNIOR, A.M., et al., "Regenerated cellulose scaffolds: Preparation, characterization and toxicological evaluation," Carbohydr. Polym., v. 136, pp. 892-898, 2016.

[6] SALAMA, A. "Cellulose/calcium phosphate hybrids: New materials for biomedical and environmental applications," Int. J. Biol. Macromol., v. 127, pp. 606-617, 2019.

[7] KOKUBO, T., TAKADAMA, H. "How useful is SBF in predicting in vivo bone bioactivity?," Biomaterials, v. 27, n. 15, pp. 2907-2915, 2006.

[8] XU, K., GUO, L., YE, H. "A naturally optimized mass transfer process: The stomatal transpiration of plant leaves,” J. Plant Physiol., vol. 234-235, no. November 2018, pp. 138-144, 2019.

[9] ORYAN, A., KAMALI, A., MOSHIRI, A., et al.,"Chemical crosslinking of biopolymeric scaffolds: Current knowledge and future directions of crosslinked engineered bone scaffolds," Int. J. Biol. Macromol., v. 107, n. PartA, pp. 678-688, 2018.

[10] HOKKANEN, S., BHATNAGAR, A., REPO, E. et al., "Calcium hydroxyapatite microfibrillated cellulose composite as a potential adsorbent for the removal of $\mathrm{Cr}(\mathrm{VI})$ from aqueous solution," Chem. Eng. J., v. 283, pp. 445-452, 2016.

[11] NGUYEN, H.M., PHAN, C.M., SEN, T. "Degradation of sodium dodecyl sulfate by photoelectrochemical and electrochemical processes," Chem. Eng. J., vo. 287, pp. 633-639, 2016.

[12] HARDIN, J.A., JONES, C.L., MANESS, N.O. et al., "Rapid in situ Quantification of Leaf Cuticular Wax Using FTIR-ATR and DSC," in ASABE Meeting Presentation, 2013, no. April 2017.

[13] ADAMS, L.A., ESSIEN, E.R., ADESALU, A.T., et al., "Bioactive glass 45S5 from diatom biosilica" J Sci Adv Mat Dev, v. 2, n. 4, pp. 476-482. Dec. 2017.

[14] KUMAR, A., LEE, Y., KIM, D., et al., "Effect of crosslinking functionality on microstructure, mechanical properties, and in vitro cytocompatibility of cellulose nanocrystals reinforced poly (vinyl alcohol)/sodium alginate hybrid scaffolds" Int J Biological Macromolecules, v. 95, pp. 962-973. Feb. 2017.

[15] USALA, R.L., VERBALIS, J.G. "Disorders of water and sodium homeostasis and bone," Cur Opi Endocrine Metabolic Research, v.3, pp. 83-92. Dec. 2018.

[16] HENCH, L.L., WILSON, J. An Introduction to Bioceramics, 2 ed., Singapore. World Scientific Publishing Co., 1993.

[17] FUKUZAKI, S. "Mechanisms of Actions of Sodium Hypochlorite in Cleaning and Disinfection Processes," Biocontrol Science, v. 11, n. 4, pp. 147-157. Dec. 2006.

[18] HIDALGO, E., BARTOLOME, R., DOMINGUEZ, C. "Cytotoxicity mechanisms of sodium hypochlorite in cultured human dermal fibroblasts and its bactericidal effectiveness," Chemico Biological Interactions, v. 139, pp. 265-282. 2002.

[19] CHO, S., CHANG, M., LEE, Y. et al., "Changes in the Residual Chlorine Content of Fresh-cut Lettuce during Storage,” J. Korean Soc. Appl. Biol. Chem, v. 53, n. 3, pp. 337-341. Jun. 2010.

[20] ESSNER, M.D., JAVED, A., ELEAZER, P.D. "Effect of sodium hypochlorite on human pulp cells: an in vitro study. Oral Surgery, Oral Medicine," Oral Pathology Oral Radiology and Endodontology, v. 112, n. 5, pp. 662-666. Nov. 2011.

[21] WANG, X., MA, J., WANG, Z. et al., "Reinvestigation of membrane cleaning mechanisms using NaOCl: Role of reagent diffusion,” J. Membrane Science, v. 550, pp. 278-285. Mar. 2018. 
[22] ANTONY, N., SHERINE, H.B., RAJENDRAN, S. "Inhibition and Biocide Actions of Sodium Dodecyl Sulfate-Zn2+ System for the Corrosion of Carbon Steel in Chloride Solution," Port. Electrochim. Acta, vol. 28, no. 1, pp. 1-14, 2010.

[23] QIU, J.; LI, X.Y.; LIU, P.; et al., “[Analysis of leave FTIR of nine kinds of plants from Rosaceae with genetic relationship]. - PubMed - NCBI," Guang Pu Xue YU Guang Pu Fen Xi, vol. 34, no. 2, pp. 344-349, 2014.

[24] WULANDARI, W.T., ROCHLIADI, A., ARCANA, I.M. "Nanocellulose prepared by acid hydrolysis of isolated cellulose from sugarcane bagasse,” IOP Conf. Ser. Mater. Sci. Eng., v. 107, n. 1, 2016.

[25] STORCK, C.R., NUNES, G.L., OLIVEIRA, B.B., et al., "Leaves, stalk, pell and seeds of vegetables: nutritional composition, utilization and sensory analysis in food preparations," Ciência Rural, v. 43, n. 3, pp. $537-43,2013$.

[26] RAHMATI, M., MOZAFARI, M. "Protein adsorption on polymers,” Mater. Today Commun., v. 17, n. April, pp. 527-540, 2018

[27] RATNER, J., HOFFMAN, B.D., SCHOEN, A.F.; et al.,Biomaterials science : an introduction to materials in medicine. Elsevier Academic Press, 2004.

[28] CANEVAROLO JUNIOR, S.V. Técnicas de caracterização de polímeros., 1st ed. São Carlos - SP, Artliber, 2004.

\section{ORCID}

Paula Pereira de Souza Vaz Rudolf Huebner

Hermes de Souza Costa https://orcid.org/0000-0003-3964-7568

https://orcid.org/0000-0003-2613-304X

https://orcid.org/0000-0001-7086-8196 